\title{
Pemanfaatan E-journal oleh Mahasiswa: Kajian Analisis Sitasi Terhadap Tesis Mahasiswa Klaster Saintek Universitas Gadjah Mada**)
}

\author{
Purwani Istiana; \\ email: nina@ugm.ac.id \\ Sri Purwaningsih* \\ Email: spurwaningsih@ugm.ac.id
}

\begin{abstract}
Universitas Gadjah Mada Library provides various information resources either in printed or electronic formats. The Library has subscribed to electronic information resources in the form of ejournal databases. The availability and utilization of these resources need to be evaluated. This study is a citation analysis of theses of the students from science and technology cluster of Universitas Gadjah Mada in 2015. It is aimed at identifying: 1) types of information resources used by the students in thesis writing, 2)intensity of the utilization of e-journal information resources by the students, and 3) the availability of the required information in the databases subscribed by UGM Library. The object of the study consisted of 7,925 citation derived from 222 theses of the students from science and technology cluster UGM. Data were obtained from documentation. This study used citation analysis to analyze all citations. The result of the study showed types of information resources used by the students in thesis writing were books, journals, theses, websites, proceedings, government regulations/acts, others (maps, learning materials, guides to laboratory practice), research reports and dissertations and papers. Books were information resources mostly used. Journals utilized in thesis writing comprised as much as 25\% (1,997 citations) and 84\% (1,685 citations) of the journals were English. As many as 1,078 citations (64\%) were available and 607 citations (36\%) unavailable in the journals subscribed by UGMLibrary.
\end{abstract}

Keywords: Utilization, E-Journals; Citation Analysis; Availability

*) Perpustakaan Fakultas Geografi UGM

**) Pemenang Hibah Penelitian Perpustakaan UGMtahun 2016

\section{A. PENDAhULUAN}

Perpustakaan Universitas Gadjah Mada (selanjutnya disingkat Perpustakaan UGM) merupakan salah satu perpustakaan perguruan tinggi negeri di Indonesia. Pengembangan koleksi merupakan salah satu program kegiatan Perpustakaan UGM. Sesuai kebutuhan dan perkembangan teknologi informasi, Perpustakaan UGM melanggan e-journal dan $e$ book. Melanggan e-book dan e-journal menjadi pilihan yang tepat agar koleksi yang dilanggan atau dibeli perpustakaan dapat dimanfaatkan oleh lebih banyak mahasiswa atau dosen dalam waktu bersamaan. Beberapa database yang dilanggan oleh Perpustakaan UGM antara lain, ScienceDirect, SpringerLink, Proquest, JSTOR, APS Journal, Emerald dan sebagainya. Melalui Single Sign On, mahasiswa dapat mengakses seluruh koleksi jurnal elektronik yang dilanggan Perpustakaan UGM.
Penggunaan sumber-sumber informasi oleh mahasiswa antara lain digunakan sebagai rujukan dalam penulisan tugas akhir. Penyusunan tugas akhir (skripsi, tesis dan disertasi) oleh mahasiswa memerlukan sumber rujukan yang relevan, baik sumber informasi tercetak maupun elektronik. Sumber informasi elektronik cukup banyak disediakan oleh Perpustakaan UGM, demikian juga, sumber informasi tercetak. Mahasiswa dapat meminjam buku-buku tercetak di hampir semua perpustakaan fakultas yang ada di UGM. Sumber informasi elektronik dapat diakses oleh mahasiswa darimana saja sepanjang mereka terhubung dalam jaringan internet dan memiliki alamat e-mail UGM.

Kita ketahui bersama bahwa untuk melanggan jurnal elektronik dalam satu tahun diperlukan anggaran yang tidak sedikit. Selain untuk biaya langganan, Perpustakaan UGM 
juga melaksanakan kegiatan sosialisasi database e-journal yang dilanggan kepada mahasiswa. Oleh karena itu, perlu dilakukan evaluasi terhadap pemanfaatan jurnal elektronik oleh mahasiswa. Sejauhmana mahasiswa telah memanfaatkan jurnal elektronik yang telah dilanggan Perpustakaan UGM.

Pemanfaatan sumber informasi tercetak maupun sumber informasi elektronik oleh mahasiswa secara nyata dapat kita cermati di dalam daftar pustaka tugas akhir mahasiswa. Pemanfaatan sumber informasi di dalam daftar pustaka tugas akhir mahasiswa mencerminkan tingkat pemanfaatan koleksi perpustakaan oleh mahasiswa. Dengan melakukan analisis terhadap daftar pustaka tugas akhir mahasiswa, dapat diketahui sumber informasi apa saja yang digunakan mahasiswa. Hal ini merupakan salah satu bentuk kajian yang dapat dilakukan untuk mengetahui pemanfaatan sumber informasi elektronik yang dilanggan Perpustakaan UGM oleh mahasiswa. Berdasarkan paparan di atas peneliti merumuskan masalah dalam penelitian ini ialah seberapa besar pemanfaatan e-journal oleh mahasiswa. Rumusan masalah diperinci dengan dua pertanyaan penelitian sebagai berikut:

a. Jenis sumber informasi apa saja yang digunakan mahasiswa dalam penulisan tugas akhir.

b. Seberapa besar tingkat pemanfaatan jurnal elektronik (e-journal) oleh mahasiswa dalam penulisan tugas akhir.

Tujuan dan manfaat penelitian antara lain:

a. Untuk mengetahui sumber informasi apa saja yang dimanfaatkan mahasiswa dalam penulisan tugas akhir tesis.

b. Untuk mengetahui pemanfaatan jurnal elektronik oleh mahasiswa dalam penyusunan tugas akhir tesis.

Hasil penelitian diharapkan dapat dimanfaatkan Perpustakaan UGM sebagai bahan evaluasi terhadap pemanfaatan sumber informasi elektronik terutama e-journal yang selama ini sudah dilanggan dan yang telah disosialisasikan kepada mahasiswa.

Berdasarkan rumusan masalah dan tujuan dalam penelitian maka kajian pemanfaatan $e$ journal oleh mahasiswa dapat dilakukan terhadap seluruh karya ilmiah yang telah dihasilkan oleh seluruh sivitas akademika UGM. Dengan berbagai pertimbangan yang terkait dengan proses penelitian, keterbatasan waktu, sumber daya yang dimiliki dan juga tujuan yang ingin dicapai maka penelitian ini dibatasi karya akhir mahasiswa yang berupa tesis mahasiswa Klaster Sain dan Teknik Tahun 2015 menurut data Unggah Mandiri Perpustakaan UGM.

\section{B. TINJAUAN PUSTAKA}

\section{Jurnal Elektronik (E-Journal)}

Jurnal elektronik merupakan salah satu jenis koleksi perpustakaan. Jurnal elektronik telah banyak dilanggan oleh perpustakaan perguruan tinggi. Perpustakaan Nasional dan Direktorat Pendidikan Tinggi juga melanggan jurnal elektronik untuk memenuhi kebutuhan masyarakat. Tujuan melanggan jurnal elektronik adalah agar masyarakat dapat dengan mudah mengakses hasil-hasil penelitian terbaru yang sangat bermanfaat untuk pengembangan ilmu pengetahuan dan teknologi di Indonesia. Jurnal elektronik dilanggan dalam bentuk database yang berisi banyak judul jurnal yang terdiri dari artikel-artikel hasil penelitian. Database yang dilanggan oleh beberapa perguruan tinggi di Indonesia antara lain, Ebsco, ScienceDirect, SpringerLink, Proquest, $J S T O R$, dan lain-lain.

\section{Evaluasi Koleksi Perpustakaan}

Pengembangan koleksi perpustakaan merupakan salah satu kegiatan yang bertujuan menyediakan koleksi perpustakaan bagi penggunanya. Evaluasi koleksi merupakan bagian dari kegiatan pengembangan koleksi. Kosasih (2009) menyatakan bahwa evaluasi koleksi perpustakaan antara lain untuk menjawab pertanyaan tentang seberapa besar manfaat koleksi perpustakaan bagi komunitas yang dilayani. Evaluasi koleksi dapat dilakukan melalui koleksi itu sendiri dan melalui pemanfaatannya.

\section{Analisis Sitasi}

Citation menurut Reitz (2006) ialah acuan tertulis dari sebuah karya atau bagian sebuah karya yang dihasilkan oleh pengarang, penyunting, komposer dan sebagainya, yang dengan jelas mengidentifikasi suatu dokumen, 
di mana acuan karya itu diperoleh. Untuk menghasilkan sebuah karya akademik (skripsi, tesis dan disertasi) sebagai salah satu syarat untuk menyelesaikan studi, mahasiswa memerlukan berbagai sumber informasi. Berbagai sumber informasi yang digunakan ialah buku, jurnal, prosiding, makalah, karya akademik, e-book, e-journal dan sebagainya. Pada proses penulisan karya akademik, mahasiswa akan mencantumkan sumber informasi yang digunakan pada bagian daftar pustaka (referensi). Mahasiswa Klaster Saintek Universitas Gadjah Mada menggunakan beberapa sumber referensi dan pada akhir karya akademik akan menuliskan seluruh sitasi yang digunakan dalam daftar pustaka.

Alasan seorang penulis mensitasi karya penulis sebelumnya antara lain untuk memperkuat sebuah temuan, memberitahu pembaca tentang penelitian yang sudah dilakukan, menerangkan konsep atau teori, menunjukkan karya lain yang berbeda dan sebagainya (Andriani, 2002:32). Hal ini menunjukkan bahwa karya akademik yang baru akan selalu mengacu atau merujuk pada karya terdahulu yang terkait. Satu tema penelitian untuk sebuah karya akademik yang akan disusun oleh seorang mahasiswa akan selalu ada komunikasi ilmiah dengan tema penelitian yang sama atau hampir sama yang telah ada sebelumnya. Dikatakan oleh Ramesh (2000:171) bahwa mensitasi merupakan salah satu bentuk komunikasi ilmiah.

Sumber informasi yang disitasi berarti sumber informasi tersebut penting bagi penulis untuk mendukung karya akademik yang dihasilkan. Keberadaan sumber informasi yang disitasi perlu diperhatikan perpustakaan, sebagai bahan pertimbangan dalam pengembangan koleksi perpustakaan. Oleh karena itu perlu dilakukan kajian analisis sitasi atas pemanfaatan sumber informasi dalam penulisan karya akhir mahasiswa.

Analisis sitasi merupakan bagian dari bibliometrika. Bibliometrika ialah satu kajian yang bersifat kuantitatif, menerapkan metode statistika dan matematika terhadap bentuk komunikasi tertulis dan komunikasi terekam lainnya (Rupadha, 2011). Sulistyo-Basuki (2002) menyebutkan bahwa pada dasarnya bibliometrika terbagi atas dua kelompok besar yaitu kelompok yang mengkaji distribusi publikasi dan yang mengkaji analisis sitasi.
Analisis sitasi merupakan penghitungan terhadap karya yang disitasi oleh penulis yang digunakan untuk mendukung dalam penyusunan karya tulis yang dikerjakan.

Kajian analisis sitasi merupakan salah satu metode penelitian kuantitatif yang dapat diterapkan secara luas, untuk mengenali literatur yang digunakan dalam kegiatan ilmiah (Rupadha, 2011). Dengan demikian penelitian terhadap karya akhir tesis dengan menggunakan metode analisis sitasi merupakan pilihan yang tepat, agar perpustakaan dapat memperoleh gambaran nyata sumber informasi yang digunakan mahasiswa dalam penyusunan karya akhir.

\section{Kajian Pustaka}

Penelitian tentang pemanfaataan koleksi atau keterpakaian koleksi perpustakaan telah banyak dilakukan. Pengelola perpustakaan telah menyadari bahwa hasil penelitian tentang pemanfaatan koleksi akan bermanfaat bagi perpustakaan untuk meningkatan layanan ketersediaan koleksi bagi penggunanya. Penelitian untuk mengetahui tingkat pemanfaatan koleksi perpustakaan dapat dilakukan dengan berbagai metode dan beberapa objek kajian.

Beberapa penelitian tentang pemanfaatan koleksi perpustakaan antara lain:

1. Rahma (2015) meneliti pemanfaatan koleksi umum Perpustakaan Universitas Negeri Padang (UNP) dengan menggunakan metode dokumenter. Peneliti melakukan pemeriksaan secara langsung data sirkulasi pemanfaatan koleksi umum di Perpustakaan Universitas Negeri Padang. Data yang telah dikumpulkan dianalisis menggunakan teknik analisis deskriptif. Hasil penelitian menunjukkan bahwa tingkat keterpakaian koleksi umum di Perpustakaan UNP ratarata perbulan adalah 4.998 eksemplar, mahasiswa dari Fakultas Ilmu Sosial yang paling tinggi dalam pemakaian koleksi perpustakaan. Hasil penelitian Rahma (2015) ini juga menunjukkan peminjaman koleksi umum masih rendah jika dibandingkan dengan jumlah koleksi yang tersedia dan jumlah mahasiswa UNP.

2. Penelitian lain tentang pemanfaatan koleksi perpustakaan dilakukan oleh 
Maryam (2015) dengan menggunakan analisis sitasi yang bertujuan untuk mengetahui tingkat ketersediaan buku yang disitir dalam laporan penelitian dosen di Perpustakaan UIN Syarif Hidayatullah. Penelitian ini mengambil seluruh populasi laporan penelitian dosen tahun 2014 sebanyak 217. Peneliti melakukan analisis sitasi daftar pustaka yang digunakan oleh dosen UIN Syarif Hidayatullah Jakarta pada laporan penelitian tahun 2014. Hasil penelitian menunjukkan bahwa pada penyusunan laporan penelitian dosen UIN Syarif Hidayatullah Jakarta buku masih dominan dijadikan sumber rujukan. Ketersediaan literatur yang disitir di Perpustakaan UIN Syarif Hidayatullah Jakarta sebesar $33.4 \%$, sisanya $66,6 \%$ literatur tidak tersedia. Penelitian ini mengambil kesimpulan bahwa tingkat ketersediaan koleksi UIN Jakarta masih kurang dalam memenuhi kebutuhan penelitian dosen.

3. Penelitian yang juga menggunakan kajian analisis sitasi ialah penelitian Anggraini (2013) yang mendekripsikan karakteristik literatur yang disitir dalam tesis mahasiswa Pascasarjana Program Studi Ilmu Biomedik tahun 2012 dan juga ketersediaannya di Perpustakaan Fakultas Kedokteran Universitas Andalas. Anggraini menganalisis karakteristik literatur yang disitir, meliputi, jenis literatur, judul literatur yang sering disitir, pengarang yang sering disitir, bahasa literatur yang sering disitir, dan paro hidup literatur. Ketersediaan literatur yang disitir, Anggraini mencocokkan data literatur yang disitir pada daftar koleksi Perpustakaan Fakultas Kedokteran Universitas Andalas. Hasil Penelitian menunjukkan bahwa jenis literatur yang paling sering disitir pada penulisan tesis mahasiswa adalah buku ( $47,05 \%)$. Literatur yang disitir 53,18\% berbahasa Indonesia. Ketersediaan literatur yang disitir sebesar $57,55 \%$ tersedia di perpustakaan.

4. Penelitian lain dengan menggunakan analisis sitiran dilakukan oleh Himawanto (2015) terhadap sitiran yang terdapat pada Jurnal Scientific Contribution Oil and Gas tahun 2010-2014. Tujuan analisis sitasi yang dilakukan ialah untuk mengetahui keterpakaian rujukan jurnal, karakteristik sitiran terbitan berkala yang digunakan, dan kekuatan sitasi judul dan penulis. Hasil penelitian antara lain menunjukkan bahwa artikel dalam Jurnal Scientific Contribution Oil and Gas tahun 2010-2014 telah menyitir 566 acuan primer, bersumber dari 234 jurnal ilmiah yang mayoritas terbitan luar negeri. Pengarang yang agresif memanfaatkan terbitan berkala ilmiah adalah Oberlin Sidjabat dan Morina, yang keduanya berasal dari Pusat Riset Migas.

Berdasarkan paparan kajian pustaka di atas, maka penelitian yang akan dilakukan ada persamaan dengan penelitian yang dilakukan sebelumnya, yaitu tentang pemanfaatan koleksi perpustakaan. Persamaan ini menunjukkan bahwa evaluasi tingkat pemanfaatan perlu dilakukan untuk memberi masukkan bagi Perpustakaan UGM dalam pengembangan koleksi, terutama koleksi jurnal elektronik yang telah dilanggan. Ketiga penelitian yaitu Rahma (2015), Maryam (2015), dan Anggraini (2013), ketiganya melakukan pengecekkan sejumlah sitiran dengan ketersediaan koleksi pada koleksi cetak di perpustakaan. Pada penelitian yang akan dilakukan ini, akan melakukan pengecekkan pada koleksi online database yang dilanggan oleh Perpustakaan UGM. Artinya penelitian ini akan memiliki perbedaan yang cukup signifikan dengan penelitian terdahulu dan akan memberikan kontribusi yang berbeda pula, yaitu dalam evaluasi koleksi e-journal yang dilanggan Perpustakaan UGM.

\section{METODE PENELITIAN}

Jenis penelitian yang akan digunakan dalam penelitian ini ialah deskriptif kuantitatif. Penelitian ini akan menggambarkan pemanfaatan jurnal elektronik oleh mahasiswa pada penulisan tesis. Subyek penelitian ialah tesis mahasiswa Klaster Saintek tahun 2015 berdasarkan tesis yang masuk pada data unggah mandiri karya akhir mahasiswa. Keterbatasan waktu penelitian, biaya dan tenaga dalam pelaksanaan penelitian tidak dapat dilakukan untuk semua klaster yang ada di UGM. Universitas Gadjah Mada mengelompokkan fakultas yang ada dalam empat kelompok, yaitu klaster saintek, klaster kesehatan, klaster agro dan klaster sosial-humaniora. Obyek penelitian 
ialah sejumlah sitasi yang terdapat dalam tesis klaster saintek yang digunakan sebagai sampel penelitian.

\section{Sampel Penelitian}

Penelitian ini akan mengambil 222 sampel tesis mahasiswa Klaster Saintek tahun 2015. Berikut ini jumlah tesis pada masing-masing fakultas dalam Klaster Saintek, berdasarkan data unggah mandiri karya akhir mahasiswa di Perpustakaan UGM (Tabel 1)

Tabel 1. Jumlah Tesis Klaster Saintek Tahun 2015

\begin{tabular}{cc}
\hline Fakultas & Jumlah Populasi \\
\hline Geografi & 78 \\
\hline MIPA & 362 \\
\hline Teknik & 730 \\
\hline Jumlah & $\mathbf{1 1 7 0}$
\end{tabular}

Sumber: Data Unggah Mandiri Perpustakaan UGM

Pengambilan sampel didasarkan pada tabel penentuan jumlah sampel dari populasi dengan taraf kesalahan 10\% ( Sugiono, 2008). Berdasarkan perhitungan dengan taraf kesalahan 10\% maka sampel untuk masingmasing populasi ditampilkan pada tabel 2 .

Tabel 2. Jumlah Sampel Penelitian

\begin{tabular}{lc}
\hline Fakultas & Sampel \\
\hline Geografi & 20 \\
\hline MIPA & 67 \\
\hline Teknik & 135 \\
\hline Jumlah & $\mathbf{2 2 2}$ \\
\hline
\end{tabular}

Jumlah sampel yang telah ditampilkan pada tabel 2 cukup representatif mewakili populasi.

Teknik pengambilan sampel yang akan dilakukan dalam penelitian ini ialah secara acak. Masing-masing kelompok populasi akan diambil sampel secara acak, sehingga masingmasing tesis memiliki peluang yang sama untuk dijadikan sampel penelitian.

\section{Teknik Pengumpulan Data}

Pengumpulan data dalam penelitian ini menggunakan teknik dokumentasi. Peneliti akan menghimpun seluruh data sitasi yang tercantum dalam daftar pustaka tesis yang digunakan sebagai sampel penelitian. Prosedur pengumpulan data ialah sebagai berikut: a. Menghimpun data seluruh tesis Klaster Saintek, pada data unggah mandiri Perpustakaan UGM

b. Setelah ditentukan sampel penelitian dengan cara acak, kemudian menghimpun daftar pustaka yang ada dalam karya ilmiah tesis.

c. Melakukan pendataan seluruh data sitasi yang ada pada daftar pustaka.

d. Melakukan pengecekan jurnal yang disitasi pada database e-journal yang dilanggan Perpustakaan UGM, melalui SUMMON

\section{Analisis data}

Analisis data yang akan digunakan dalam penelitian ini adalah analisis sitasi. Setelah melakukan pengumpulan data dengan mencermati data dokumentasi, data sitasi tesis, maka peneliti selanjutnya akan melakukan analisis sitasi. Tahapan yang dilakukan dalam analisis sitasi adalah sebagai berikut:

a. Mengelompokkan data sitasi berdasarkan jenis sumber informasi yang digunakan.

b. Menghitung jumlah sitasi yang diperoleh oleh masing-masing jenis sumber informasi.

c. Penentukan peringkat jumlah jenis sumber informasi yang disitasi.

d. Menghitung jumlah jurnal elektronik yang tersedia pada Database E-Journal Perpustakaan UGM.

e. Melakukan persentase atas jenis sumber informasi yang digunakan dan jurnal yang tersedia pada Database E-Journal Perpustakaan UGM.

f. Menyajikan seluruh data yang sudah dianalisis dalam bentuk tabel.

g. Menarik kesimpulan

\section{HASIL DAN PEMBAHASAN}

\section{Deskripsi Data Analisis}

Analisis data pada kajian bersumber dari 222 tesis mahasiswa Klaster Saintek UGM yang tercatat pada data unggah mandiri Perpustakaan UGM tahun 2015. Berdasarkan sitasi pada daftar pustaka tesis tersebut, diperoleh 7.925 sitasi. Rincian perolehan sitasi dapat dilihat pada tabel 3: 
Tabel 3. Perolehan Jumlah Sitasi

\begin{tabular}{ccc}
\hline Fakultas & Jumlah Tesis & Jumlah Sitasi \\
\hline Geografi & 20 & 876 \\
\hline MIPA & 67 & 2.135 \\
\hline Teknik & 135 & 4.914 \\
\hline Jumlah & 222 & 7.925 \\
\hline
\end{tabular}

Sumber: Data Primer yang Diolah, 2016

\section{Sumber Informasi yang Digunakan dalam Penulisan Tesis}

Hasil analisis sitasi terhadap 7.925 sitasi tesis tersebut diperoleh beberapa jenis sumber informasi yang digunakan (yang disitir) mahasiswa dalam penulisan tesis, dalam tabel 4 .

Tabel 4. Jenis Sumber Informasi yang Disitir

\begin{tabular}{llrr}
\hline No. & Jenis Literatur & $\begin{array}{l}\text { Jumlah } \\
\text { Sitasi }\end{array}$ & \multicolumn{1}{c}{$\%$} \\
\hline 1 & Buku & 3.241 & 41 \\
\hline 2 & Jurnal & 1.997 & 25 \\
\hline 3 & Tesis & 617 & 7.8 \\
\hline 4 & Website & 563 & 7.1 \\
\hline 5 & Makalah & 405 & 5.1 \\
\hline 6 & Prosiding & 261 & 3.3 \\
\hline 7 & Peraturan/Undang-Undang & 232 & 3 \\
\hline 8 & Lain-Lain & 173 & 2.2 \\
\hline 9 & Terbitan Pemerintah & 172 & 2.17 \\
\hline 10 & Laporan Penelitian & 103 & 1.3 \\
\hline 11 & Disertasi & 83 & 1.05 \\
\hline 12 & Skripsi & 78 & 0.98 \\
\hline & Jumlah & 7.925 & 100 \\
\hline
\end{tabular}

Sumber: Data Primer yang Diolah, 2016

Berdasarkan hasil analisis sitasi ada 12 sumber informasi dalam kajian ini, yaitu buku, jurnal, makalah, tesis, disertasi, skripsi, website, prosiding, laporan penelitian, peraturan/ undang-undang, terbitan pemerintah dan lainlain. Termasuk dalam kelompok sumber informasi lain-lain yaitu petunjuk praktikum, peta dan sebagainya yang tidak dapat dikelompokkan dalam 11 jenis sumber informasi yang telah disebutkan.

Sumber informasi yang paling banyak digunakan yakni buku sebesar $41 \%$, diikuti jurnal, tesis, sumber dari website, makalah, prosiding, peraturan perundang-undangan, lainlain, terbitan pemerintah, disertasi, dan skripsi. Hasil kajian ini hampir sama dengan kajian yang dilakukan Maryam (2015) terhadap laporan penelitian dosen di UIN Syarif Hidayatullah tahun 2014, yang menunjukkan bahwa buku merupakan sumber informasi yang dominan digunakan rujukan dalam penulisan laporan penelitian dosen. Hasil kajian in i berbeda dengan penelitian yang dilakukan Abeyrathne (2015) terhadap disertasi Fakultas Pertanian Universitas Peradeniya. Hasil penelitian Abeyrathne menunjukkan bahwa dalam penulisan disertasi mahasiswa lebih banyak menggunakan sumber informasi jurnal.

Sumber informasi yang digunakan (disitasi) mahasiswa berdasarkan bahasanya, terbagi dalam sumber informasi yang berbahasa Inggris dan bahasa Indonesia. Tabel 5 menunjukkan bahasa sumber informasi yang digunakan mahasiswa dalam penulisan tesis.

Tabel 5. Bahasa Sumber Informasi yang Digunakan

\begin{tabular}{lrr}
\hline Bahasa & Sitasi & $\%$ \\
\hline Indonesia & 3.200 & 40,4 \\
\hline Inggris & 4.725 & 59.6 \\
\hline Jumlah Sitasi & 7.925 & 100 \\
\hline
\end{tabular}

Sumber : Data Primer yang Diolah, 2016

Mahasiswa dalam penulisan tesis lebih banyak menggunakan bahasa Inggris daripada bahasa Indonesia. Hal ini berbeda dengan penelitian yang dilakukan oleh Anggraini (2013) terhadap tesis mahasiswa pascasarjana Program Studi Biomedik Fakultas Kedokteran Universitas Andalas, yang lebih banyak menggunakan sumber informasi berbahasa Indonesia. Artinya mahasiswa telah memiliki kemampuan bahasa Inggris yang cukup memadai, sehingga tidak mengalami kesulitan dalam pemanfatan sumber informasi berbahasa Inggris.

\section{Pemanfatan Jurnal Elektronik oleh Mahasiswa}

Jurnal merupakan salah satu sumber informasi yang sangat disarankan dalam penulisan tesis. Dalam sebuah jurnal memuat artikel-artikel hasil penelitian terbaru yang perlu dirujuk supaya dalam melakukan penelitian, mahasiswa telah memiliki referensi yang cukup atas penelitian yang telah dilakukan sebelumnya dengan tema yang terkait. Rujukan dari sebuah jurnal juga akan memperkaya referensi bagi mahasiswa atas penelitian terbaru yang telah dilakukan, sehingga akan melakukan penelitian yang berbeda dengan penelitian sebelumnya. Berdasarkan hasil analisis data 
sitasi pada tesis mahasiswa Klaster Saintek, diperoleh bahwa total jumlah sitasi jurnal sebesar 1997 (25\%). Walaupun tidak ada ketentuan jumlah penggunaan jurnal dalam penulisan tesis, namun menurut peneliti, mahasiswa dalam penulisan tesis perlu lebih banyak memanfaatkan sumber informasi berupa artikel hasil penelitian yang terdapat dalam jurnal. Jurnal memberikan informasi terbaru berbagai hasil penelitian yang terkait dengan tema penelitian bahkan memungkinkan informasi tentang teori baru yang diperoleh dalam sebuah hasil penelitian. Hal ini berbeda dengan sumber referensi buku, yang dalam penerbitan sebuah buku memerlukan waktu yang lebih lama.

Dari jumlah 1997 sitasi (25\% dari keseluruhan sitasi yang digunakan), jurnal berbahasa Indonesia sebanyak $312(16 \%)$ dan sitasi jurnal berbahasa Inggris sebanyak 1.685 (84\%). Pemanfaatan jurnal sebagai sumber referensi dalam penulisan tesis dapat dilihat pada tabel 6 .

Tabel 6. Pemanfaatan Jurnal dalam Penulisan Tesis

\begin{tabular}{lrr}
\hline Bahasa jurnal & Jumlah Sitasi & $\mathbf{\%}$ \\
\hline Indonesia & 312 & 16 \\
\hline Inggris & 1.685 & 84 \\
\hline Jumlah Total Sitasi & & \\
Jurnal & 1.997 & 100 \\
\hline
\end{tabular}

Sumber: Data Primer yang Diolah, 2016

Mahasiswa lebih banyak memanfaatkan jurnal berbahasa Inggris, hal ini bisa dipahami karena koleksi jurnal yang dimiliki perpustakaan lebih banyak koleksi jurnal berbahasa Inggris. Perpustakaan melanggan berbagai database bidang ilmu yang dapat dimanfaatkan mahasiswa.

\section{Ketersediaan Sumber Informasi Jurnal pada Database yang Dilanggan Perpustakaan UGM}

Untuk mengetahui ketersediaan jurnal yang digunakan mahasiswa dalam penulisan tesis, kajian ini fokus pada jurnal berbahasa Inggris, mengingat tujuan penelitian ini adalah mengetahui pemanfaatan jurnal yang dilanggan Perpustakaan UGM oleh mahasiswa dalam penulisan tesis. Penelusuran dan pengecekan sitasi jurnal menggunakan aplikasi SUMMON yang juga dilanggan oleh perpustakaan.
Gambar 2 merupakan tampilan aplikasi SUMMON yang dilanggan Perpustakaan UGM.

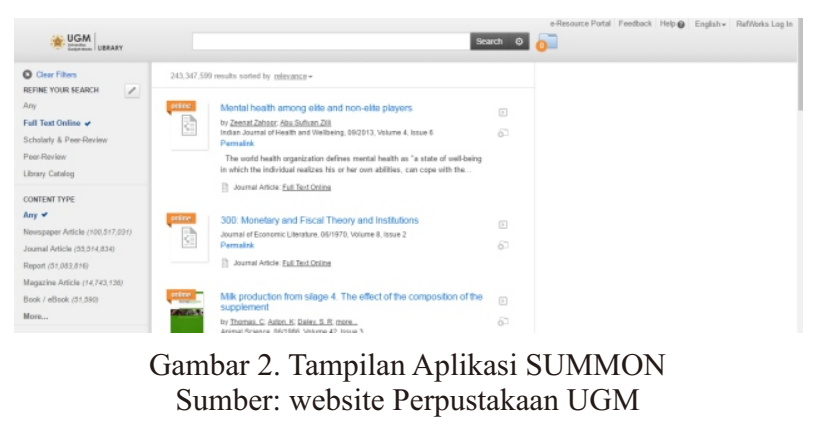

Hasil Penelusuran 1.685 sitasi jurnal melalui aplikasi SUMMON menunjukkan bahwa 1078 (64\%) sitasi jurnal tersedia di perpustakaan dan 607 (36\%) sitasi tidak tersedia. Tabel 7 menunjukkan ketersediaan jurnal yang digunakan mahasiswa pada database yang dilanggan oleh Perpustakaan UGM.

Hasil kajian ini berbeda dengan temuan yang dilakukan oleh Maryam (2015) yang mengkaji sitasi pada laporan penelitian dosen UIN Syarif Hidayatullah. Maryam (2015) menemukan bahwa sumber informasi yang digunakan dosen dalam penulisan laporan penelitian $66,6 \%$ tidak tersedia pada koleksi Perpustakaan UIN Syarif Hidayatullah Jakarta. Artinya koleksi perpustakaan masih kurang dalam mendukung kinerja dosen terutama dalam penulisan laporan penelitian.

Tabel 7. Ketersediaan Jurnal pada Database Dilanggan Perpustakaan UGM

\begin{tabular}{lrr}
\hline $\begin{array}{l}\text { Ketersediaan Pada } \\
\text { Database }\end{array}$ & Jumlah Sitasi & $\%$ \\
\hline Tersedia & & \\
\hline Tidak Tersedia & 1078 & 64 \\
\hline Jumlah & 607 & 36 \\
\hline
\end{tabular}

Sumber: Data Primer yang Diolah, 2016

Hasil kajian terlihat pada tabel 7 menunjukkan angka yang lebih tinggi dari temuan kajian yang dilakukan Anggraini (2013) terhadap sitasi pada tesis mahasiswa Program Studi Biomedik, Fakultas Kedokteran Universitas Andalas. Anggraini (2013) menemukan bahwa sitasi yang digunakan 57,55\% tersedia di Perpustakaan Fakultas Kedokteran Universitas Andalas. 
Ketersediaan koleksi juga menunjukkan bahwa perpustakaan telah memberikan kontribusi yang nyata dalam mendukung proses penulisan tesis bagi mahasiswa Klaster Saintek Universitas Gadjah Mada, yakni sebesar 64\% dalam pemenuhan kebutuhan referensi terutama jurnal. Kajian tentang ketersediaan koleksi merupakan satu bentuk evaluasi terhadap koleksi perpustakaan yang selama ini disediakan bagi mahasiswa. Seperti telah diungkapkan oleh Kosasih (2009) bahwa evaluasi koleksi antara lain untuk menjawab pertanyaan tentang seberapa besar manfaat koleksi perpustakaan bagi komunitas yang dilayani.

\section{E. PENUTUP}

Simpulan kajian ini sebagai berikut:

a. Sumber informasi yang dimanfaatkan mahasiswa dalam penulisan tugas akhir tesis yaitu buku $41 \%$, jurnal $25 \%$, tesis $7,8 \%$, website $7,1 \%$, makalah $5,1 \%$, prosiding $3.3 \%$ peraturan/undang-undang $3 \%$, lain-lain (peta, pedoman praktikum, bahan ajar) $2,2 \%$, terbitan pemerintah $2,17 \%$, disertasi $1,05 \%$, dan skripsi $0,98 \%$.

b. Bahasa sumber informasi yang digunakan mahasiswa dalam penulisan tesis lebih banyak menggunakan sumber informasi berbahasa Inggris $59,6 \%$ dan $40,4 \%$ sumber informasi berbahasa Indonesia.

c. Mahasiswa lebih banyak menggunakan jurnal berbahasa Inggris 1.685 sitasi (84\%) daripada jurnal berbahasa Indonesia 312 sitasi $(16 \%)$.

d. Jurnal berbahasa Inggris 1.685 sitasi, sebesar $64 \%$ tersedia pada pada database yang dilanggan oleh Perpustakaan UGM dan sebesar 36\% jurnal tidak tersedia pada database yang dilanggan Perpustakaan UGM.

\section{SARAN}

Berdasarkan kajian yang telah dilakukan ada beberapa rekomendasi atau saran yang perlu disampaikan yaitu:

a. Pemanfaatan jurnal oleh mahasiswa dalam penulisan tugas akhir tesis sebesar 25\% masih perlu ditingkatkan, mengingat koleksi jurnal yang dilanggan oleh Perpustakaan UGM cukup memadai. b. Peningkatan penggunaan jurnal oleh mahasiswa dalam penulisan tesis dapat dilakukan dengan kegiatan literasi informasi bagi mahasiswa program Magister (S2), sehingga perlu lebih diintensifkan sosialisasi dan pelatihan pemanfaatan jurnal yang dilanggan oleh Perpustakaan UGM.

c. Jurnal-jurnal yang banyak disitasi mahasiswa artinya jurnal tersebut penting bagi mahasiswa, sehingga langganan jurnal tersebut perlu dipertahankan.

d. Temuan lain dalam kajian ini ialah beragamnya cara penulisan daftar pustaka dalam satu departemen atau fakultas oleh mahasiswa. Masukkan bagi masing-masing fakultas yang diambil sebagai sampel kajian ini agar penulisan daftar pustaka menjadi perhatian bagi dosen pembimbing, mengingat penulisan daftar pustaka (bibliografi) merupakan bagian yang cukup penting dalam sebuah penulisan ilmiah.

e. Mengingat keterbatasan waktu dan biaya, data yang digunakan dalam kajian ini hanya data tesis tahun 2015. Untuk penelitian lanjutan perlu dikaji dengan data mendalam sehingga dapat dilihat kecenderungan pemanfaatan jurnal dalam beberapa tahun.

\section{DAFTAR PUSTAKA}

Abeyrathne, Dilani Kanishka. 2015. "Citation Analysis of Dissertations for Collection Development". Collection Building, 34 (2): 30-40.

Andriani, Juznia. 2002. Studi Kualitatif Mengenai Alasan Menyitir Dokumen: Kasus pada Lima Mahasiswa Program Pascasarjana IPB. Jurnal Perpustakaan Pertanian Vol. 11 No. 2. hal.

Anggraini, Lusi. Bakhtaruddin Nst. 2013. Evaluasi Ketersediaan Koleksi dengan Menggunakan Analisis Sitiran terhadap Tesis Mahasiswa Pascasarjana Program Studi Ilmu Biomedik Tahun 2012 di Perpustakaan Fakultas Kedokteran Universitas Andalas. Jurnal Ilmu Informasi Perpustakaan dan Kearsipan Vol. 2 No. 1. Hal. 159-168

Himawanto, 2015. Kajian Sitiran Terbitan Berkala pada Kegiatan Riset Minyak dan Gas Bumi yang Terekam Media Terakreditasi. Baca: Jurnal Dokumentasi dan Informasi Vol 36 No. 2. hal. 125-140 
Kosasih, Aa., 2009. Mengoptimalkan Pengembangan Koleksi. https://scholar. google.co.id/scholar?hl=id\&q=pengemba ngan + koleksi $+\&$ btnG $=$. Download: 27 April 2016

Maryam, S., 2015. Evaluasi Koleksi Perpustakaan UIN Syarif Hidayatullah Jakarta Berdasar Analisis Sitasi Penelitian Dosen, LP2M UIN SyarifHidayatullah, Jakarta

Rahma, Elva; Malta Nelisa; Marlina Marlini., 2015. Evaluasi Tingkat Keterpakaian Koleksi Umum di Perpustakaan Universitas Negeri Padang. Jurnal Pustaka Budaya Vol 2 No. 1. http://ejurnal. unilak.ac.id /index.php/ pb/article/view/114. Download: 28 April 2016

Ramesh, L.S.R.C.V. and A.V.S.S. Nagaraju., 2000. Citation Analysis of the Indian Journal of Information, Library and Society. Indian Journal Information Library \& Society, Vol. 13 No. 3-4. hal. 171-179
Reitz, Joan M., 2002., ODLIS: Online Disctionary for Library and Information Science. http://vlado.fmf.unilj.si/pub/networks/data /dic/odlis/odlis.pdf

Rupadha, I Komang., 2011., Memahami Karakteristik Kebutuhan Informasi Peneliti dengan Metode Analisis Sitasi. Makalah. Seminar dan Temu Ilmiah Pustakawan, Universitas Mataram.

Sugiono, 2008., Metode Penelitian Kuantitatif, Kualitatifdan $R \& D$. Alfabeta, Bandung

Sulistyo-Basuki., 2002. Bibliometrik, Sainsmetrik dan Informetrika. Makalah untuk Kursus Informetrika. Pusat Studi Jepang Universitas Indonesia, Jakarta 